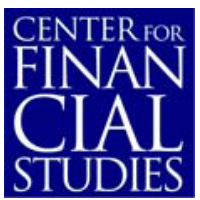

No. $2010 / 01$

The Impact of Macroeconomic News on Quote Adjustments, Noise, and Informational Volatility

Nikolaus Hautsch, Dieter Hess, and David Veredas 


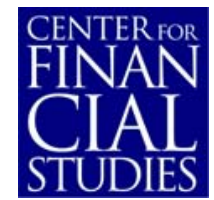

\section{Center for Financial Studies}

The Center for Financial Studies is a nonprofit research organization, supported by an association of more than 120 banks, insurance companies, industrial corporations and public institutions. Established in 1968 and closely affiliated with the University of Frankfurt, it provides a strong link between the financial community and academia.

The CFS Working Paper Series presents the result of scientific research on selected topics in the field of money, banking and finance. The authors were either participants in the Center's Research Fellow Program or members of one of the Center's Research Projects.

If you would like to know more about the Center for Financial Studies, please let us know of your interest.
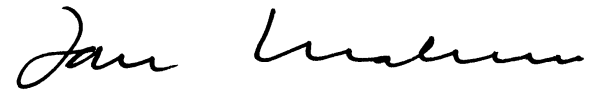

Prof. Dr. Jan Pieter Krahnen 


\title{
The Impact of Macroeconomic News on Quote Adjustments, Noise, and Informational Volatility*
}

\author{
Nikolaus Hautsch ${ }^{1}$, Dieter Hess ${ }^{2}$, \\ and David Veredas ${ }^{3}$
}

January 2010

\begin{abstract}
:
We study the impact of the arrival of macroeconomic news on the informational and noise-driven components in high-frequency quote processes and their conditional variances. Bid and ask returns are decomposed into a common ("efficient return") factor and two market-side-specific components capturing market microstructure effects. The corresponding variance components reflect informationdriven and noise-induced volatilities. We find that all volatility components reveal distinct dynamics and are positively influenced by news. The proportion of noise-induced variances is highest before announcements and significantly declines thereafter. Moreover, news-affected responses in all volatility components are influenced by order flow imbalances.
\end{abstract}

JEL Classification: C32, G14, E44

Keywords: Efficient Return, Macroeconomic Announcements, Microstructure Noise, Informational Volatility.

\footnotetext{
* For helpful comments and discussions with thank Torben Andersen, Tim Bollerslev, Angelo Ranaldo, Carsten Tanggard, and Peter Boswijk as well as the seminar and conference participants at University of Aarhus, Humboldt-Universität zu Berlin, University of Konstanz, Stanford University and Imperial Business School, London. The first author acknowledges support from the Deutsche

Forschungsgemeinschaft (DFG) via the Collaborative Research Center 649 'Economic Risk'. The third author gratefully acknowledge financial support from the Belgian National Bank and the IAP P6/07 contract, from the IAP programme (Belgian Scientific Policy), 'Economic policy and finance in the global economy'. The authors are members of ECORE, the recently created association between CORE and ECARES.

1 School of Business and Economics as well as CASE - Center for Applied Statistics and Economics, Humboldt-Universität zu Berlin, Quantitative Products Laboratory (QPL), Berlin, and Center for Financial Studies (CFS), Frankfurt.

2 Department of Economics, University of Cologne as well as Center for Financial Research (CFR).

3 ECARES - European Centre for Advanced Research in Economics and Statistics, Université Libre de Bruxelles.
} 


\section{Introduction}

The arrival of news and the processing of (non-anticipated) information is a major driving force of asset price volatility. Though the availability of financial high-frequency data allows researchers to study the impact of news on the price process at the micro level, the ultimate effect on volatility is still unclear. In fact, the measurement of highfrequency volatility is a non-trivial issue, as it is overshadowed by noise stemming from market frictions - so-called market microstructure effects. Therefore, it is unclear how much of a news-implied increase in asset price volatility is ultimately due to larger fluctuations of the underlying "efficient" return and how much is due to "microstructure noise" inducing a higher instability of bid and ask quotes. Disentangling both components is necessary to estimate the ultimate effect of announcements on the efficient asset return volatility and to produce a more complete picture of high-frequency price discovery.

The objective of this paper is to address this fundamental question and to analyze what proportion of volatility changes around the arrival of macroeconomic news is due to "informational" volatility (i.e., the volatility of the efficient price) and how much is due to noise volatility (induced by quote fluctuations around the efficient price). We develop a structural model decomposing bid and ask quote returns into three conditionally heteroscedastic and news-dependent components: a common efficient return component and two market-side-specific noise components capturing noise-driven deviations between observed and efficient returns.

Using this methodological framework, we analyze the following major research questions: (i) How strong is the impact of news on the information and noise components of volatility, and how much does this effect depend on the magnitude and the precision of surprises? (ii) How large is the relative share of noise in conditional quote return volatilities, and how does it change around announcements? (iii) Can trading volume and net order flow (partly) explain the impact of news on informational and noise volatility?

We propose a state-space model decomposing bid and ask quote returns into a common efficient return component and two market-side-specific factors capturing deviations from efficient returns. The three unobserved return components are assumed to follow a VAR(1) model with conditionally heteroscedastic errors. Conditional means and vari- 
ances are augmented by regressors capturing the impact of news announcements and the state of the market. The model is estimated by quasi maximum likelihood using the Kalman filter. To reduce the computational complexity due to the need of highly parameterized conditional variances, we suggest a two-step estimation procedure. In the first stage, the model is (consistently) estimated assuming homoscedastic errors. In the second stage, we estimate the conditional variances using the updated Kalman filter residuals. The conditional variances are specified as multiplicative error models in the spirit of Engle (2002), with four components capturing the effect of the announcements, volatility dynamics, deterministic time effects around news announcements, and the state of the market.

The analysis of macroeconomic news' effects on asset return volatility is a central area of research in empirical finance. One of the early studies examining the effect of macroeconomic news on volatility is that of Ederington and Lee (1993), who analyze five-minute sample variances across announcement days and find that volatility is significantly higher in the interval immediately following an announcement but rapidly declines afterwards. Christie-David and Chaudhry (1999) show that volatility seems to be more persistent if the underlying asset is more liquid. Hautsch and Hess (2002) and Andersen, Bollerslev, Diebold, and Vega (2003) stress the importance of disentangling the impact of news on both the first and the second conditional moments of the return process. Both studies document a strong and persistent increase in the conditional volatility following an announcement while controlling for shifts in prices.

However, in both theoretical and empirical literature, the effects of news on efficient and noise-driven volatility components are widely unexplored. The literature on heterogeneous beliefs suggests that uncertainty about the equilibrium price level is created by disagreement among traders about the precision of the news or about its interpretation (e.g., Harris and Raviv, 1993, Kandel and Pearson, 1995, and Kandel and Zilberfarb, 1999). According to this literature, greater disagreement among traders leads to higher trading activity. As long as this induces a higher liquidity supply, we expect that market microstructure frictions become less important causing a reduction of the relative importance of noise volatility. A related argument is provided by the literature on speculative trading suggesting that volatility and trading volume results primarily from heterogeneous information among market participants (e.g., Kyle, 1985, or Foster and Viswanathan, 1996). According to Pasquariello and Vega (2007), 
more diverse information among traders allows them to trade more cautiously on their own private information. If, however, a public signal is announced, it becomes more difficult to exploit private (prior) information cautiously. Consequently, traders trade more aggressively, market liquidity increases, and the noise volatility component should decline.

Our econometric model contributes to the literature on modeling quote processes on financial markets. In a seminal paper, Hasbrouck (1991) studies the price impact of trades by proposing a VAR model for returns and signed trades. Hasbrouck (1993) proposes decomposing security transaction prices into a random walk component and stationary error components. Engle and Patton (2004) and Escribano and Pascual (2006) extend the framework by Hasbrouck (1991) and propose a vector error correction model for bid and ask quotes with the spread acting as the co-integrating vector. Madhavan, Richardson, and Roomans (1997) introduce a structural model of price formation by decomposing transaction price volatility into volatility arising from news shocks (trade-unrelated information) and volatility arising from market frictions such as price discreteness, asymmetric information, and real frictions. Pascual and Veredas (2010) introduce a state-space model of price and volatility formation in the spirit of Madhavan, Richardson, and Roomans (1997) by decomposing quotes into a common stochastic trend - the efficient price - and transitory noisy components. Zhang, Russell, and Tsay (2008) propose a similar decomposition inducing an asymmetric rounding mechanism generating discrete bid and ask quotes from a latent continuous process.

Finally, our study also contributes to the literature on volatility estimation using highfrequency data. An important issue in this literature is to address the impact of market microstructure frictions occurring on high sampling frequencies (see Hansen and Lunde, 2006, or Barndorff-Nielsen, Hansen, Lunde, and Shephard, 2006 among others). Indeed, the estimates of our structural model for quote returns provide additional insights into the dependence structure of market microstructure noise and the variances thereof.

Our empirical analysis employs monthly announcements on nonfarm payrolls and unemployment rates issued by the U.S. labor market report. It is well documented that these figures are among the most influential scheduled releases. To quantify the magnitude of non-anticipated information (so-called "surprises"), we use consensus analyst forecasts. The impacts of news on prices are quantified based on minute-by-minute quotes of the German Bund futures traded on Eurex. Being closely related to long-term 
interest rates, Bund futures react very sensitively to macroeconomic announcements. Though the home market of these futures is in Germany, several studies clearly document that U.S. labor market figures are the most important announcements (e.g., Andersen, Bollerslev, Diebold, and Vega, 2003, 2007 or Andersson, Overby, and Sebestyén, 2009). Furthermore, Eurex is an electronic system providing precise and detailed data not only on trade prices but also on quotes, volumes, and market depth.

The most important findings of our analysis are as follows: first, news announcements have a highly positive impact on both efficient and noise volatility. Instantly after the announcement, both volatility components reveal significant jumps followed by a gradual decline. The relationship between efficient volatility and the magnitude of surprises is concave. Conversely, for noise volatility, a convex relationship is found. This supports the hypothesis that very large surprises are interpreted to be less reliable and thus induce smaller (or even negative) marginal increases in prices and efficient volatility and a relatively higher share of noise volatility. Second, noise and efficient volatility show around news announcements different patterns resulting in a higher proportion of noise before the release. This share significantly drops instantly after the announcement and reaches a minimum approximately 30 minutes later. Third, the net order flow has a significantly positive effect on both volatility components. This impact becomes even stronger directly after news arrival. Fourth, the noise components reveal distinct serial dependencies confirming results for stock markets shown by, e.g., Hansen and Lunde (2006). Finally, our results show that apart from news-induced variations, noise variances reflect distinct GARCH effects. The overall share of noise volatility in total volatility is approximately $3 \%$, reflecting comparably low spread variations in Bund futures trading.

The remainder of the paper is structured as follows. In Section 2, we introduce the econometric model. Section 3 presents the data and the construction of underlying variables. Empirical results are presented and discussed in Section 4. Section 5 analyzes the impact of news on the proportion of the efficient variance in the total quote variances. Section 6 concludes. 


\section{A State-Space Model for Bid and Ask Returns}

In this section, we introduce a new type of structural microstructure model for bid and ask quote returns. Define $a_{t}$ and $b_{t}$ as the log best ask and best bid quotes, respectively, at time $t=1, \ldots, T$. Then, $r_{a, t}:=a_{t}-a_{t-1}$ and $r_{b, t}:=b_{t}-b_{t-1}$ denote the corresponding ask and bid returns. We assume that $\mathbf{r}_{t}:=\left(r_{a, t}, r_{b, t}\right)$ is driven by the sum of a common return component $m_{t}$, market-side-specific components $S_{a, t}$ and $S_{b, t}$ as well as $k_{1}$ announcement-related regressors $\mathbf{x}_{t}^{r}$ and $k_{2}$ market liquidity variables $\mathbf{z}_{t}^{r}$ capturing the state of the market. Accordingly, the bivariate process $\mathbf{r}_{t}:=\left(r_{a, t}, r_{b, t}\right)^{\prime}$ is described by

$$
\mathbf{r}_{t}=\mathbf{H} \boldsymbol{\xi}_{t}+\mathbf{B}^{\prime} \mathbf{x}_{t}^{r}+\mathbf{D}^{\prime} \mathbf{z}_{t}^{r}
$$

where

$$
\mathbf{H}:=\left(\begin{array}{lll}
1 & 0 & 1 \\
0 & 1 & 1
\end{array}\right)
$$

and $\boldsymbol{\xi}_{t}:=\left(S_{a, t} . S_{b, t}, m_{t}\right) . \mathbf{B}:=\left(\boldsymbol{\beta}_{a}, \boldsymbol{\beta}_{b}\right)$ is a $k_{1} \times 2$ matrix of coefficients capturing the effect of news on returns and $\mathbf{D}:=\left(\boldsymbol{\delta}_{a}, \boldsymbol{\delta}_{b}\right)$ is a $k_{2} \times 2$ matrix of coefficients associated with the state of the market around announcements.

The common component $m_{t}$ is assumed to capture the underlying (unobservable) efficient return driving both ask and bid returns. By contrast, $S_{a, t}$ and $S_{b, t}$ are associated with time-variations in market-side-specific spread variations and capture deviations between $m_{t}$ and $\mathbf{r}_{\mathbf{t}}$. Following the terminology in the literature, we refer to $S_{a, t}$ and $S_{b, t}$ as ask and bid noise returns, respectively.

The underlying framework is similar to the model by Pascual and Veredas (2010), who decompose bid and ask prices in a common random walk component and idiosyncratic noise factors. However, here we directly model returns. This approach is more natural and sensible in the given context, as it removes the need to account for stochastic trends in prices and allows focussing the analysis on event windows around the announcements. The dynamics of the unobservable return components are assumed to be driven by a vector autoregressive (VAR) process of order one, i.e.,

$$
\boldsymbol{\xi}_{t}=\boldsymbol{\mu}+\mathbf{F} \boldsymbol{\xi}_{t-1}+\varepsilon_{t},
$$


where $\boldsymbol{\mu}=(0,0, c)$ is a $3 \times 1$ vector, and $\mathbf{F}$ is a $3 \times 3$ matrix of the form

$$
\mathbf{F}=\left(\begin{array}{ccc}
\phi_{a} & 0 & 0 \\
0 & \phi_{b} & 0 \\
0 & 0 & \phi_{m}
\end{array}\right)
$$

According to traditional structural microstructure models of price formation, efficient returns should follow a white noise process implying $\phi_{m}$ and $c$ to be zero. Conversely, noise returns are assumed to have a zero mean and are expected to show mean-reverting behavior resulting in negative coefficients $\phi_{a}$ and $\phi_{b}$. The diagonal specification of $\mathbf{F}$ rules out dynamic spill-overs between the latent components. Preliminary analyses based on more flexible specifications of $\mathbf{F}$ show that this restriction is widely confirmed by the data. As we observe that the off-diagonal elements are rather small and difficult to identify, we see the diagonal specification as being sufficiently flexible while being computationally tractable.

Note that we include the regressors $\mathbf{x}_{t}^{r}$ and $\mathbf{z}_{t}^{r}$ directly in (1). This implies that the effect of $\mathbf{x}_{t}^{r}$ and $\mathbf{z}_{t}^{r}$ on $r_{a, t}$ and $r_{b, t}$ is present only in period $t$. Because the regressors contain period-specific variables, this specification is most appropriate and eases the interpretation of regressor effects. Alternatively, or additionally, we could include components $\mathbf{C}^{\prime} \mathbf{x}_{t}^{r}$ and $\mathbf{E}^{\prime} \mathbf{z}_{t}^{r}$ in (2), with $\mathbf{C}$ and $\mathbf{D}$ denoting corresponding parameter matrices. The regressors would then be included in the autoregression and would enter the model in terms of an infinite lag structure, making interpretation more difficult. ${ }^{1}$

The vector of innovations $\varepsilon_{t}:=\left(\varepsilon_{a, t}, \varepsilon_{b, t}, \varepsilon_{m, t}\right)$ is assumed to be conditionally normally distributed, i.e.,

$$
\varepsilon_{t} \mid \mathcal{F}_{t-1} \sim \mathcal{N}\left(\mathbf{0}, \boldsymbol{\Sigma}_{t}\right)
$$

where $\mathcal{F}_{t}$ denotes the information set up to $t, \mathbf{0}$ is a $3 \times 1$ vector of zeros and $\boldsymbol{\Sigma}_{t}:=$ $\operatorname{diag}\left(h_{a, t}, h_{b, t}, h_{m, t}\right){ }^{2}$ The components $h_{a, t}, h_{b, t}, h_{m, t}$ are referred to as (conditional) ask and bid noise variances as well as the efficient variance, respectively. Each variance component is specified in terms of a multiplicative error specification (see, among

\footnotetext{
${ }^{1}$ Moreover, factor-specific effects of $\mathbf{x}_{t}^{r}$ and $\mathbf{z}_{t}^{r}$ in (2) are only individually identifiable as long as either $\phi_{m} \neq 0$ or $\phi_{a} \neq 0$ and $\phi_{b} \neq 0$. In the case of a joint identification of $\mathbf{B}$ and $\mathbf{C}$ as well as of $\mathbf{D}$ and $\mathbf{E}$ it is even required that $\phi_{m} \neq 0$ and $\phi_{a} \neq \phi_{m} \neq 0$ and $\phi_{b} \neq \phi_{m} \neq 0$. Otherwise, because of the linearity of (1), $r_{a, t}$ and $r_{b, t}$ are effectively driven by the same set of regressors twice.

${ }^{2}$ Following Pascual and Veredas (2010) we could allow $\boldsymbol{\Sigma}_{t}$ to be non-diagonal. However, because time-varying covariances are not in the ultimate objective of the present study, we leave this extension for future research.
} 
others, Engle, 2002, Engle and Rangel, 2008, or Hautsch, 2008):

$$
h_{i, t}=\text { dyn }_{i, t} \text { ton }_{i, t} \text { liq }_{i, t} \text { news } s_{i, t}, \quad i=\{a, b, m\},
$$

where

$$
\begin{aligned}
\operatorname{dyn}_{i, t} & :=\exp \left[\omega_{i}+\theta_{i} \ln d y n_{i, t-1}+\alpha_{i}\left(\frac{\left|\varepsilon_{i, t-1}\right|}{\sqrt{d y n_{i, t-1}}}-\sqrt{\frac{2}{\pi}}\right)\right] \\
\operatorname{ton}_{i, t} & :=\exp \left[\sum_{j=1}^{3} \psi_{i, j}^{s} \sin (2 \pi j \tau)+\psi_{i, j}^{c} \cos (2 \pi j \tau)\right] \\
\operatorname{liq}_{i, t} & :=\exp \left(\boldsymbol{\gamma}_{i}^{\prime} \mathbf{z}_{t}^{v}\right) \\
\text { news }_{i, t} & :=\exp \left(\varrho_{i}^{\prime} \mathbf{x}_{t}^{v}\right)
\end{aligned}
$$

The first component, $d y n_{i, t}$, captures dynamics in the variance processes according to an EGARCH structure (Nelson, 1991). The second component, ton $_{i, t}$, captures deterministic volatility patterns around the announcement dates. We refer them to 'time-ofnews' (ton) effects and model them using a flexible Fourier form (Gallant, 1981) of order three. ${ }^{3}$ Here $\tau=t / T \in[0,1]$ is the standardized time during the event window, where $T$ denotes the number of (one-minute) time intervals around the announcement. The third component, $l i q_{i, t}$, contains regressors $\mathbf{z}_{t}^{v}$ capturing market activity and liquidity with corresponding parameters $\gamma_{i}$. Finally, news $s_{i, t}$ consists of news-specific regressors $\mathbf{x}_{t}^{v}$ with parameters $\varrho_{i}^{\prime}$.

Equations (1), (2) and (3) form a linear state-space model that can be estimated with the Kalman filter. An (efficient) one-step estimation of the model is numerically and computationally expensive when the number of variance regressors $\left(\mathbf{x}_{t}^{v}\right.$ and $\left.\mathbf{z}_{t}^{v}\right)$ and the number of Fourier terms are high. To reduce the computational complexity, we suggest a two-step estimation procedure. Two-step estimations in volatility modeling are quite common and are performed in Schwert (1989), Andersen, Bollerslev, Diebold, and Wu (1995), Beine, Lahaye, Laurent, Neely, and Palm (2006) and Engle and Rangel (2008), among others. Pascual and Veredas (2010) also suggest proceeding in two steps in a state-space setting similar to ours. ${ }^{4}$ In the first step, we consistently estimate the model

\footnotetext{
${ }^{3}$ This is mostly supported by information criteria. To check the robustness, we also estimated other orders for the Fourier series. The results, available under request, barely change.

${ }^{4}$ Alternatively, the model might be estimated using MCMC techniques as used in a similar context by Zhang, Russell, and Tsay (2008). However, given our highly parameterized conditional variances this would also be computationally very demanding.
} 
using a state-space system with constant variances. Normality allows us to estimate the factors using the Kalman filter as well as the parameters using the corresponding error prediction decomposition (see Harvey, 1992). Using pseudo-maximum likelihood (PML) arguments in an exponential family setting, the estimates are consistent, though not efficient, under distributional misspecification as long as the conditional means are correctly specified (see Gouriéroux, Monfort, and Trognon, 1984). In the second step, we estimate the variance-covariance matrix based on the updated Kalman filter residuals, $e_{i, t}=\mathrm{E}\left[\varepsilon_{i, t}^{*} \mid \mathcal{F}_{t}\right], i=\{a, b, m\}$. Because $\boldsymbol{\Sigma}_{t}$ is assumed to be diagonal, the estimation of $\boldsymbol{\Sigma}_{t}$ boils down to univariate EGARCH models. ${ }^{5}$

The model (1)-(3) can be written in reduced form as

$$
\begin{aligned}
& r_{a, t}=\frac{c}{1-\phi_{m}}+\boldsymbol{\beta}_{a}^{\prime} \mathbf{x}_{t}^{r}+\boldsymbol{\delta}_{a}^{\prime} \mathbf{z}_{t}^{r}+\varepsilon_{a, t}+\varepsilon_{m, t}+\sum_{j=1}^{\infty} \phi_{a}^{j} \varepsilon_{a, t-j}+\sum_{j=1}^{\infty} \phi_{m}^{j} \varepsilon_{m, t-j}, \\
& r_{b, t}=\frac{c}{1-\phi_{m}}+\boldsymbol{\beta}_{b}^{\prime} \mathbf{x}_{t}^{r}+\boldsymbol{\delta}_{b}^{\prime} \mathbf{z}_{t}^{r}+\varepsilon_{b, t}+\varepsilon_{m, t}+\sum_{j=1}^{\infty} \phi_{b}^{j} \varepsilon_{b, t-j}+\sum_{j=1}^{\infty} \phi_{m}^{j} \varepsilon_{m, t-j},
\end{aligned}
$$

which is a Vector $\mathrm{MA}(\infty)$ model with exogenous regressors and a common error term induced by the efficient return. If efficient returns have a zero mean and are uncorrelated, the unique source of serial dependence in (5) and (6) are the noise terms. Thus the equations simplify to

$$
\begin{aligned}
& r_{a, t}=\boldsymbol{\beta}_{a}^{\prime} \mathbf{x}_{t}^{r}+\boldsymbol{\delta}_{a}^{\prime} \mathbf{z}_{t}^{r}+\varepsilon_{a, t}+\varepsilon_{m, t}+\sum_{j=1}^{\infty} \phi_{a}^{j} \varepsilon_{a, t-j}, \\
& r_{b, t}=\boldsymbol{\beta}_{b}^{\prime} \mathbf{x}_{t}^{r}+\boldsymbol{\delta}_{b}^{\prime} \mathbf{z}_{t}^{r}+\varepsilon_{b, t}+\varepsilon_{m, t}+\sum_{j=1}^{\infty} \phi_{b}^{j} \varepsilon_{b, t-j} .
\end{aligned}
$$

Conditioning on past information, (contemporaneous) news arrival and the state of the market, the conditional (co-)variances are given by

$$
\begin{aligned}
\sigma_{i, t}^{2} & =\mathrm{V}\left[r_{i, t} \mid \mathcal{F}_{t-1}, \mathbf{x}_{t}^{r}, \mathbf{z}_{t}^{r}, \mathbf{x}_{t}^{v}, \mathbf{z}_{t}^{v}\right]=h_{i, t}+h_{m, t}, \quad i \in\{a, b\} \\
\sigma_{a b, t} & =\operatorname{Cov}\left[r_{a, t}, r_{b, t} \mid \mathcal{F}_{t-1}, \mathbf{x}_{t}^{r}, \mathbf{z}_{t}^{r}, \mathbf{x}_{t}^{v}, \mathbf{z}_{t}^{v}\right]=h_{m, t} .
\end{aligned}
$$

Following Engle and Patton (2004), a parameterization of $r_{a, t}$ and $r_{b, t}$ also implies a parameterization of changes in the $\log$ spread $s p r_{t}:=a_{t}-b_{t}$ and the log mid-quote

\footnotetext{
${ }^{5}$ Theoretically, the second-step estimators should account for the estimation error involving $e_{i, t}$. However, due to the large number of observations, we do not expect that this uncertainty qualitatively affects our results.
} 
$m q_{t}:=0.5\left(a_{t}+b_{t}\right)$. Pre-multiplying (1) by the matrix $(1:-1,0.5: 0.5)$ yields the reduced form

$$
\begin{aligned}
\Delta s p r_{t} & =S_{a, t}-S_{b, t}+\left(\boldsymbol{\beta}_{a}-\boldsymbol{\beta}_{b}\right)^{\prime} \mathbf{x}_{t}^{r}+\left(\boldsymbol{\delta}_{a}-\boldsymbol{\delta}_{b}\right)^{\prime} \mathbf{z}_{t}^{r} \\
\Delta m q_{t} & =c+0.5\left(S_{a, t}+S_{b, t}\right)+m_{t}+0.5\left(\boldsymbol{\beta}_{a}-\boldsymbol{\beta}_{b}\right)^{\prime} \mathbf{x}_{t}^{r}+0.5\left(\boldsymbol{\delta}_{a}-\boldsymbol{\delta}_{b}\right)^{\prime} \mathbf{z}_{t}^{r},
\end{aligned}
$$

where $\Delta$ denotes the first-difference operator. Correspondingly, the conditional variances of $\Delta s p r_{t}$ and $\Delta m q_{t}$ are given by

$$
\begin{aligned}
\sigma_{\Delta s p r, t}^{2} & =\mathrm{V}\left[\Delta s p r_{t} \mid \mathcal{F}_{t-1}, \mathbf{x}_{t}^{r}, \mathbf{z}_{t}^{r}, \mathbf{x}_{t}^{v}, \mathbf{z}_{t}^{v}\right]=h_{a, t}+h_{b, t} \\
\sigma_{\Delta m q, t}^{2} & =\mathrm{V}\left[\Delta m q_{t} \mid \mathcal{F}_{t-1}, \mathbf{x}_{t}^{r}, \mathbf{z}_{t}^{r}, \mathbf{x}_{t}^{v}, \mathbf{z}_{t}^{v}\right]=0.5\left(h_{a, t}+h_{b, t}\right)+h_{m, t} .
\end{aligned}
$$

The conditional variance of spread changes thus equals the sum of the noise variances. Consequently, if the noise variances are zero, the spread is constant, and quote returns and efficient returns coincide corresponding to the mid-quote return. As a result, its conditional variance simply equals $h_{m, t}$.

\section{Data}

The model is estimated based on intraday data of the German Bund futures traded on Eurex. We extract data from Eurex's time and sales records including prices as well as best bid and ask quotes. Because the data directly stem from a computerized matching system, the information provided is very precise, including time-stamps up to the second. Trade data are available since the inception of the Bund futures contract in 1989, but we focus exclusively on data from 1995 onwards, when liquidity in the Bund futures reached a significant level (see Franke and Hess, 2000). The sample ends in December 2005, at a time when Bund futures had been the most liquid government bond futures around the world, attracting even more trading volume than the CBOT T-bond futures. For instance, in 1995, we observe on an announcement day of the U.S. employment report roughly 4 trades per minute with an average trade size of 21 contracts. This figure steadily rises and reaches 17 trades per minute with an average trade size of 77 contracts in 2005 .

We extract one-minute log bid and log ask returns from the front month contract, i.e., the most actively traded contract at a given day. We focus on an interval of \pm 80 
minutes around the announcement time of the U.S. employment report. This report is typically released at $2: 30 \mathrm{pm}$ Frankfurt time on the first Friday after the end of the month. ${ }^{6}$ We use only those employment announcement days on which no other U.S. macroeconomic report is released at the same time. Covering a sample period of 11 years from January 1995 to December 2005, we obtain 123 employment report days after excluding a few days due to overlapping releases as well as one day due to an inadvertently early release of the employment report (see Fleming and Remolona, 1999). The resulting sample consists of a time series of minute-by-minute returns observed over the concatenated series of \pm 80 minutes around the employment announcement, yielding 25,600 observations.

In accordance with a wide range of previous studies of the employment report, we restrict our attention to the nonfarm payrolls figure, which is shown to be the most influential macroeconomic news announcement. Non-anticipated information in these headline figures is measured on the basis of survey data on analysts' forecasts, provided by Standard \& Poors Global Markets (MMS) and its successor, Informa Global Markets. Initially released non-revised figures were extracted from the original monthly releases. Surprises are defined as the difference between initially announced figures and the median of analyst forecasts. Following Hautsch and Hess (2007), we exploit the fact that both figures are closely related and measure surprises in both figures in terms of percentage changes, which facilitates a direct comparison of the price impact across headline figures. That is, nonfarm payrolls surprises are defined as the deviation of the announced number of new nonfarm payrolls from the median of analyst forecasts divided by the total nonfarm payrolls in the previous month (times 100). The unemployment rate figure is already given in percentage points (i.e., the month-to-month difference in the overall unemployment rate). To capture the impact of news at specific time points during the event window, we interact the surprise variables with dummy variables indicating the periods around the announcement.

To quantify the release-specific precision of a monthly employment release, Hautsch and Hess (2007) suggest quantifying the so-called 'price-response coefficient' $\pi_{m}:=$ $\rho_{A, m} /\left(\rho_{A, m}+\rho_{F, m}\right)$. This coefficient is derived in a standard Bayesian learning model and is based on the precision (i.e., the inverse of the variance) of the estimation error

\footnotetext{
${ }^{6}$ Due to different dates of daylight savings time switches in Europe and the U.S., the employment report is released on a few occasions at 1:30pm or 3:30pm Frankfurt time.
} 
of a monthly announcement, $\rho_{A, m}$, and the precision of (analysts') forecasts of a figure, $\rho_{F, m}$ with $m$ indexing the monthly time series. A natural estimator for $\rho_{F}$ is the cross-sectional standard deviation of analysts' forecasts for a particular month. ${ }^{7}$ However, as typically no release-specific precision measure for macroeconomic announcements is available, Hautsch and Hess propose exploiting information on revisions of previous-month nonfarm payroll figures. Interpreting the magnitude of a revision as a natural indicator for the (im)precision of the previous month's figure, a one-monthahead forecast of squared revisions serves as an estimate of the (im)precision of the currently announced headline figure. Hautsch and Hess show that there is significant predictability in the squared revisions of nonfarm payroll figures, which can be captured by means of ARMA-GARCH models fitted to the time series of revisions. Following this approach, $\rho_{A, m}$ is estimated as the inverse of the conditional revision variance, $\hat{\rho}_{A, m}=\hat{\mathrm{V}}\left[R_{N F, m} \mid R_{N F, m-1}, R_{N F, m-2}, \ldots\right]^{-1}$ with $R_{N F, m}$ denoting the nonfarm payroll revision in $m$. To reduce the impact of estimation errors, we distinguish only between "precise" announcements whenever $\hat{\pi}$ is equal to or above its sample median and "imprecise" announcements otherwise.

An alternative way to quantify the precision of news is suggested by Subramanyam (1996) and put forward by Hautsch, Hess, and Müller (2008). In an extended Bayesian learning model it can be shown that the size of surprises is positively correlated with the uncertainty of news. Intuitively, large surprises are interpreted to be "too large to be true" and thus indicate a low precision of news. To capture such effects, we define a surprise to be large whenever it exceeds the $70 \%$-quantile.

Finally, we include two sets of additional regressors. First, we control for the effects of surprises in unemployment rates that are announced simultaneously. Second, to capture overall market liquidity, the vectors $\mathbf{x}_{t}^{r}$ and $\mathbf{x}_{t}^{v}$ in (1) and (4) include the net order flow and trading volume computed over one-minute intervals. The net order flow is defined as the absolute value of the difference between buyer- and seller-initiated trading volume over one-minute intervals divided by the average daily trading volume. Hence, net order flow takes on large positive values if the volume of market buy orders outweighs the corresponding sell orders relative to the 'normal' trading volume on this day. Correspondingly, the cumulated one-minute trading volume is a natural

\footnotetext{
(2007).

${ }^{7}$ See, e.g., Green (2004), Andersen, Bollerslev, Diebold, and Vega (2003), or Pasquariello and Vega
} 
proxy for the overall liquidity demand. To capture the effect that the impact of news on the underlying return processes changes over time, we allow for interactions with corresponding time dummy variables. A list of the variables is given in Table 1.

\section{Estimation Results}

\subsection{Conditional Mean Effects}

Table 2 provides the estimation results based on six different specifications, starting with a simple baseline specification (A) capturing news effects in reduced form that is subsequently augmented by variables accounting for asymmetries, the news' precision as well as market liquidity. We summarize the following findings: First, we find highly significant negative estimates for $\phi_{a}$ and $\phi_{b}$ indicating reversal effects in the noise components of the ask and bid log returns. Hence, an upward movement of $S_{a, t}$ and $S_{b, t}$ tends to be followed by a downward movement, reflecting a bouncing effect in the noise bid and ask return components. This effect essentially reflects dynamics in spread changes. As shown, for example, by Hautsch and Huang (2009), a widening of the spread induced by a transaction removing a part of the pending order volume and thus shifting the best quotes induces an increase in the liquidity supply as well as a dynamically re-balancing of the spread. Converse effects are observed after the arrival of aggressive limit orders narrowing the spread. Given the estimates of $\phi_{a}$ and $\phi_{b}$, the coefficients of the resulting MA polynomials in (5) and (6) converge to zero relatively quickly. After few lags, they are negligible, implying that the reduced-form model can be approximated by a VMA of order two or three. This is consistent with the literature that has found returns to behave like a MA process (see, e.g., Aït-Sahalia and Mykland, 2005). For the efficient return itself, we find a weakly negative (but clearly significant) serial dependence reflecting slight evidence for mean-reversion effects in efficient prices. Second, we observe strong and instantaneous effects of announcement surprises. Negative (positive) reactions on positive (negative) surprises in nonfarm payrolls (unemployment rates) is well in accordance with economic theory. These results are consistent with previous findings based on returns of U.S. T-bond futures and show that U.S. labor market announcements do have a significant impact on Eurex Bund futures trading. ${ }^{8}$

\footnotetext{
${ }^{8}$ See, e.g., Fleming and Remolona (1999b), Andersen, Bollerslev, Diebold, and Vega (2003, 2007), or Andersson, Overby, and Sebestyén (2009).
} 
It turns out that the price adjustment to nonfarm payroll surprises is completed within the first one-minute interval after the announcement (2:30-2:31pm). Note that the corresponding coefficients take on almost identical values for both bid and ask quotes. No significant effects are identifiable after the second minute. This indicates that the market processes new information very quickly. Moreover, slight evidence for significant price reactions are also observed in the interval preceding the announcement, i.e., 2:29-2:30pm. This is probably due to announcements that are published slightly before $2: 30 \mathrm{pm}$. The existence of leakage effects is quite unlikely, as the news is published under very strict lock-up conditions.

Third, we obtain strong evidence for asymmetric price reactions due to large vs. small surprises. In line with the notion of Bayesian learning the significantly negative coefficent associated with $n f_{1, L}$ indicates that (too) large surprises are indeed interpreted as being "too large to be true". However, the revision-based precision measure turns out to be insignificant. This is in contrast to the findings by Hautsch, Hess, and Müller (2008) based on U.S. T-bond futures. Hence, Bund futures traders - in contrast to traders on the T-bond 'home market' - seem to account for the size of surprises as a proxy for reliability but disregard additional information such as revisions of past figures.

Fourth, we find a remarkably strong influence of imbalances in the order flow. It turns out that standardized net order flow $\left(n o f_{t}\right)$ drives both bid and ask quote revisions during the whole 160-minute event window. The interactions with time dummies show that the impact of order flow imbalances peaks in the first minute after the announcement and is about two times as high as usual. Still, over the following four minutes, the impact is increased by about three quarters and over the next ten minutes is increased by about one quarter. This suggests that net order flow may help traders to better interpret the news, particularly, by learning about other traders' interpretation of information.

Finally, testing the individual specifications against each other by employing likelihoodratio tests (see Panel I of Table 3) indicates that the most general specification (F) is not rejected against the more parsimonious models (A) to (E). This suggests that indeed all model components jointly have explanatory power. 


\subsection{Conditional Variance Effects}

Table 4 gives the estimation results of individual EGARCH models based on the updated Kalman filter residuals stemming from the first-step estimates of specification $\mathrm{F}$ shown in Table 2. Again, we estimated different specifications, starting with a simple baseline specification (A) and successively including the individual variance components. Ultimately, specification (F) is most flexible, containing all underlying components. All specifications account for deterministic volatility patterns through the event window according to the specification of ton $_{i, t}$ in (4). Accordingly, Figures 1 and 2 show the median patterns of the estimated volatilities and their components during the event periods across all announcements based on the specifications (D) and (F). For the sake of brevity, we refrain from reporting the estimates of the component ton $_{i, t}$ in the tables, instead depicting them graphically in Panel (d) of Figures 1 and 2. Recall that ton $_{i, t}$ is an average deterministic volatility pattern that is (multiplicatively) scaled upwards or downwards by the other components. Consequently, the mean values of the components news $_{i, t}$, ton $_{i, t}$ and $l i q_{i, t}$ are by construction equal to one and cannot be interpreted on an absolute scale.

We can identify the following major findings. First, large surprises in news have an instantaneous and strongly positive impact on both efficient and noise volatility. Overall, surprises in nonfarm payrolls induce significantly stronger and more distinct reactions in volatility than does news regarding unemployment rates (see Panels A and B). As captured by the interactions of absolute surprises with corresponding time dummies, we observe the strongest effects in volatility in the minute following the arrival of the announcement. In subsequent minutes, these effects generally become smaller, less distinct and less significant. ${ }^{9}$

Second, in the case of large (nonfarm payroll) surprises (i.e., those greater than the 75\%-quantile), the efficient volatility is marginally negatively affected, whereas the noise volatility is marginally positively affected (Panels (C) and (D)). We therefore observe a concave relationship between efficient volatility and the magnitude and thus the reliability of surprises. Conversely, for noise volatilities, this relationship is convex. That is, a lower reliability of news as indicated by large surprises is reflected in noisedriven volatility rather than in efficient volatility. The former effects are obviously not

\footnotetext{
${ }^{9}$ We also tested for asymmetries with respect to the sign of the news but did not find any significant results.
} 
distinctly attributable to single one-minute intervals but are rather spread over the complete five-minute interval following the news arrival. As in the mean function, we do not observe significant impacts of the revision-driven precision variable.

Third, efficient and noise volatility react in different ways around news announcements. While efficient volatility reveals a distinct jump at the announcement that decays relatively quickly thereafter, noise volatility is particularly high shortly before and after the announcement (see Panels (a) of Figures 1 and 2). This is induced by more pronounced baseline patterns of the noise volatilities around the announcement (see Figures 1 (d) and $2(\mathrm{~d})$ ) compared to that of the efficient volatility. Additionally, it is enforced by news-driven post-announcement reversals, as depicted by Panels (c) in Figures 1 and 2. In the case of large surprises, noise volatility is significantly and instantaneously pushed up at the time of news arrival, significantly drops in subsequent trading minutes and reverts after approximately 10 minutes. We associate this pattern with an overshooting of noise-driven volatility at the time of news arrival and a corresponding re-balancing thereafter. These effects are particularly driven by news in nonfarm payrolls and to a lesser extent by unemployment rate figures.

Fourth, all volatilities reveal distinct dynamics. The parameters of the dynamic components $d y n_{i, t}$ are significant and take values in the range of what is usually found in the volatility literature. Obviously, efficient volatility is more affected by informational shocks and shows a higher impact of innovations and a lower persistence than do noise volatilities. Figures 1 (b) and 2 (b) depict the median values of the estimated EGARCH components, $d y n_{i, t}$. It turns out that the dynamic components strongly increase instantaneously after the announcement. This indicates that news effects not only are captured by the components ton $_{i, t}$ and news $s_{i, t}$ but also cause high innovations in the EGARCH process inducing persistent upward shifts of the component $d y n_{i, t}$. These effects obviously enforce the impact of news on overall ask and bid return volatility.

Fifth, the estimates in Table 2 reveal that the unconditional ask volatility is significantly higher than the bid volatility, providing first hints for asymmetries in market-sidespecific quoting activities. Interestingly, this is corroborated by corresponding asymmetries in news effects. As shown by Panels (a) and (b) of Figures 1 and 2 and reported in Table 4, the ask noise volatility reacts significantly more strongly to news. This result is robust to all specifications and preliminary data analysis. Moreover, given that we 
analyze a period covering 11 years, it is quite unlikely that this effect is driven by systematic upward or downward trends in the market. Hence, though this finding requires even more robustification, we can conclude that the ask side seems to be systematically more sensitive to news-driven information shocks than the bid side.

Sixth, net order flow has a significantly positive impact on both efficient and noise volatility. This is expected, as order flow imbalances induce variations in spreads and therefore increase noise-driven volatilities. Moreover, one-sided trading reflects the existence of information and positively affects efficient volatility. Conversely, trading volume only affects informational volatility and does not affect the noise-driven components. This is naturally explained by the strong link between volatility and trading volume, which is not only found on a daily level but also on an intraday level (see, e.g., Hautsch, 2008). Panel (e) in Figure 2 shows the median pattern of the liquidity components $l i q_{i, t}$ around the announcement. We observe that $l i q_{m, t}$ is strongly shifted upwards at the time of news arrivals. Hence, efficient volatility is increased not only due to news arrivals but also due to a rising net order flow and trading volume. This additional effect is also reflected in a higher median peak of the efficient volatility component $h_{m, t}$ (Panel (a)) compared to the effects shown in Figure 1. After the announcement, the liquidity-induced component $l i q_{m, t}$ remains at a high level and decays only slowly. Conversely, the median pattern of $l i q_{a, t}$ and $l i q_{b, t}$ decay prior to the announcement, shift upward at the event period and fluctuate around this level in subsequent periods. Interestingly, the liquidity-induced noise components reach a minimum directly before the news arrival. Hence, in this period, market activity declines and the market is seemingly awaiting information.

Finally, likelihood-ratio tests (Panel II of Table 3) suggest that the most general specification $(\mathrm{F})$ including both precision and liquidity effects dominate the more reduced models (A) to (E). This indicates the importance of accounting for market liquidity and asymmetric volatility effects when responses in volatility to news announcements are analyzed. This is particularly true for efficient volatility.

\section{Variance Ratios and Marginal Effects}

To provide insights whether news announcements have an impact on the relative proportion of the conditional efficient variance in the total conditional ask and bid return 
variance, we define so-called Information Variance Ratios $I V R_{t}^{a}$ and $I V R_{t}^{b}$, respectively, given by

$$
\begin{aligned}
I V R_{t}^{a} & :=\frac{h_{m, t}}{h_{a, t}+h_{m, t}}, \\
I V R_{t}^{b} & :=\frac{h_{m, t}}{h_{b, t}+h_{m, t}} .
\end{aligned}
$$

As their ratios approach one, the observed bid and ask returns are close to the (unobserved) efficient return, and the share of noise in returns thus decreases. If, in the limit, the bid-ask spread is constant, $h_{a, t}=h_{b, t}=0$, we have $I V R_{t}^{a}=I V R_{t}^{b}=1$.

Accordingly, the proportion of noise in (conditional) variances of spreads and midquotes are given by

$$
\begin{aligned}
I V R_{t}^{s p r, i} & :=\frac{h_{i, t}}{h_{a, t}+h_{b, t}}, \quad i \in\{a, b\}, \\
I V R_{t}^{m q} & :=\frac{h_{m, t}}{0.5\left(h_{a, t}+h_{b, t}\right)+h_{m, t}} .
\end{aligned}
$$

Obviously, $I V R_{t}^{s p r, b}+I V R_{t}^{s p r, a}=1$. If, for instance, $I V R_{t}^{s p r, a}>I V R_{t}^{s p r, b}$, more than $50 \%$ of the variability in spread changes stems from the ask side.

Figures 3 and 4 show the median values of $I V R_{t}^{a}, I V R_{t}^{m q}, I V R_{t}^{b}, I V R_{t}^{s p r, a}$ and $I V R_{t}^{s p r, b}$ around all announcements based on specifications (D) and (F). Several conclusions can be drawn: on average the information variance ratios $I V R_{t}^{a}, I V R_{t}^{b}$, and $I V R_{t}^{m q}$ are very high, mostly above $95 \%$. Hence, noise volatility is surprisingly small - but not constant. Nevertheless, the ratios are not constant during the event period but reflect a distinct pattern around the announcement. Information variance ratios start decreasing approximately 40 minutes prior to the announcement, reaching a minimum roughly 10 minutes before news arrival. This indicates that market liquidity tends to "dry out" prior to the announcement, inducing a significantly higher proportion of noise-induced quote fluctuations. Instantaneously after the announcement, the relative share of informational volatility sharply increases. This is obviously induced by a jump in efficient return volatility, which is dominating during this period. However, during the first minutes after the announcement, uncertainty in the interpretation of news induces again an increase in quoting activity and consequently a drop in information shares. After approximately 10 minutes, market uncertainty seems to be widely resolved, yielding ris- 
ing information variance ratios, which reach their maximum approximately 30 minutes after the announcement.

Furthermore, we find distinct differences between $I V R_{t}^{a}$ and $I V R_{t}^{b}$. The share of noise in quote volatilities is systematically higher on the ask side than on the bid side. This difference is most distinct in the period prior to the announcement and becomes significantly smaller after market uncertainty is widely resolved. This asymmetry is particularly striking in $I V R_{t}^{s p r, a}$ and $I V R_{t}^{s p r, b}$. As shown by Figures 3 (b) and 4 (b), the proportion of ask noise volatility in the total spread volatility is approximately $75 \%$. This ratio is widely constant during the announcement window, indicating that news barely has an effect on $I V R_{t}^{s p r, a}$ and $I V R_{t}^{s p r, b}$.

To analyze the effects of news on the resulting volatilities of bid and ask quotes, the midquote and the spread, we compute the corresponding marginal effects. In general, marginal changes in $\sigma_{a, t}^{2}$ and $\sigma_{b, t}^{2}$ induced by changes in the news-related variables $\varrho_{i}$, $i \in\{a, b, m\}$ are given by

$$
\begin{aligned}
& \frac{\partial \sigma_{a, t}^{2}}{\partial \varrho^{a}}=2\left(\varrho_{a} h_{a, t}^{2}+\varrho_{m} h_{m, t}^{2}\right), \\
& \frac{\partial \sigma_{b, t}^{2}}{\partial \varrho^{b}}=2\left(\varrho_{a} h_{b, t}^{2}+\varrho_{m} h_{m, t}^{2}\right),
\end{aligned}
$$

where $\varrho^{a}:=\left(\varrho_{a}, \varrho_{m}\right)$ and $\varrho^{b}:=\left(\varrho_{b}, \varrho_{m}\right)$. Correspondingly, we have for the marginal impacts on $\sigma_{m q, t}^{2}$ and $\sigma_{s p r, t}^{2}$,

$$
\begin{aligned}
& \frac{\partial \sigma_{m q, t}^{2}}{\partial \varrho^{m q}}=\varrho_{a} h_{a, t}^{2}+\varrho_{b} h_{b, t}^{2}+2 \varrho_{m} h_{m, t}^{2}, \\
& \frac{\partial \sigma_{s p r, t}^{2}}{\partial \boldsymbol{\varrho}^{s p r}}=2\left(\varrho_{a} h_{a, t}^{2}+\varrho_{b} h_{b, t}^{2}\right),
\end{aligned}
$$

where $\varrho^{m q}:=\left(\varrho_{a}, \varrho_{b}, \varrho_{m}\right)$ and $\varrho^{s p r}:=\left(\varrho_{a}, \varrho_{b}\right)$.

Then, for instance, the marginal effects at the minute of the announcement of a surprise in nonfarm payrolls (for simplicity denoted by $n f_{1, t}^{*}$ ) in $\sigma_{a, t}^{2}$ and $\sigma_{a, t}^{2}$ are given by

$$
\begin{aligned}
\frac{\partial \sigma_{a, t}^{2}}{\partial n f_{1, t}^{*}} & =2\left(\varrho_{a, 1} h_{a, t}^{2}+\varrho_{m, 1} h_{m, t}^{2}\right), \\
\frac{\partial \sigma_{b, t}^{2}}{\partial n f_{1, t}^{*}} & =2\left(\varrho_{b, 1} h_{b, t}^{2}+\varrho_{m, 1} h_{m, t}^{2}\right)
\end{aligned}
$$


where $\varrho_{a, 1}, \varrho_{b, 1}$ and $\varrho_{m, 1}$ are the associated coefficients of $n f_{1, t}^{*}$ in $h_{a, t}, h_{b, t}$ and $h_{m, t}$, respectively.

Consequently, the marginal impact of a large surprise in nonfarm payrolls on $\sigma_{a, t}^{2}$ and $\sigma_{b, t}^{2}$ at the minute after the announcement is given by

$$
\begin{aligned}
\frac{\partial \sigma_{a, t}^{2}}{\partial n f_{1, t}^{*}}+\frac{\partial \sigma_{a, t}^{2}}{\partial n f_{1, L, t}^{*}} & =2\left(\left(\varrho_{a, 1}+\varrho_{a, 1, L}\right) h_{a, t}^{2}+\left(\varrho_{m, 1}+\varrho_{m, 1, L}\right) h_{m, t}^{2}\right), \\
\frac{\partial \sigma_{b, t}^{2}}{\partial n f_{1, t}^{*}}+\frac{\partial \sigma_{b, t}^{2}}{\partial n f_{1, L, t}^{*}} & =2\left(\left(\varrho_{b, 1}+\varrho_{b, 1, L}\right) h_{b, t}^{2}+\left(\varrho_{m, 1}+\varrho_{m, 1, L}\right) h_{m, t}^{2}\right),
\end{aligned}
$$

where $\varrho_{a, 1, L}, \varrho_{b, 1, L}$ and $\varrho_{m, 1, L}$ are the corresponding coefficients associated with $n f_{1, L, t}^{*}$ in $h_{a, t}, h_{b, t}$ and $h_{m, t}$, respectively.

Table 5 gives the median marginal effects on bid and ask return variances (top panel) and on the midquote and spread variances (bottom panel). The median marginal effects of surprises are virtually the same for bid and ask volatilities. This symmetry reflects the dominating role of the efficient volatility, which overcompensates the askbid asymmetries found in noise variances. Moreover, the marginal effects confirm the major relationships discussed above. The largest effects are induced by surprises in nonfarm payrolls where the marginal effects of unemployment rate surprises are approximately $80 \%$ lower. Furthermore, we also observe slight reversals for $\sigma_{a, t}^{2}$ and $\sigma_{b, t}^{2}$ in the minutes after the announcement. Moreover, the marginal effects clearly reflect the nonlinear relationship between nonfarm payroll surprises and $\sigma_{a, t}^{2}$ and $\sigma_{b, t}^{2}$. For instance, based on model $(\mathrm{F})$, the increase in $\sigma_{a, t}^{2}$ due to a large surprise in nonfarm payrolls is 0.335 , while it is 1.356 if the surprise is small. This reflects the effect of a large surprise which is interpreted as an indicator for unreliable news in the spirit of Hautsch, Hess, and Müller (2008). Similar conclusions can be drawn for $\sigma_{m q, t}^{2}$. As shown above, $\sigma_{s p r, t}^{2}$ is virtually unaffected by surprises in nonfarm payrolls and unemployment rates.

\section{Conclusions}

In this paper, we have proposed a structural model of return formation that allows us to identify the underlying efficient return and market-side-specific noise components. The latter induce deviations between the observed bid and ask log returns and the common efficient return component and capture erratic and possibly liquidity-driven 
fluctuations of the best bid and ask quotes around the efficient price. The conditional variance of the efficient return is interpreted as "informational variance", capturing fluctuations in the efficient return around its conditional expectation. The latter is economically associated with differences in market participants' opinions regarding the "true" efficient return. Accordingly, the conditional variances of the bid and ask noise components reflect the extent to which the observable quote returns are liquiditydriven quote revisions. Computing the ratio between the conditional noise variance components and the resulting conditional return variance yields an easily interpretable measure of the relative noise proportion.

We allow the latent return components to follow a $\operatorname{VAR}(1)$ structure with errors driven by EGARCH models. Both the conditional mean and variance components are augmented by regressors capturing the characteristics of arriving news. The model is applied to study the impact of monthly announcements of U.S. headline figures for nonfarm payrolls and unemployment rates on one-minute ask and bid quote returns in the German Bund futures traded on Eurex. By focusing exclusively on announcement days, we analyze the impact of surprises (computed as the difference between the announced figure and the corresponding publicly announced consensus analyst forecast) in the individual figures on the conditional means of quote returns as well as on the informational and noise volatility components. Confirming previous results, we find that quotes adjust to their new levels very quickly, where the size of the price jump significantly depends on the magnitude of the surprise component in announcements. Moreover, we can summarize the following main findings: first, we observe a strong and significant increase in both efficient and noise volatilities when new information arrives in the market. Besides an (average) baseline volatility pattern revealing relatively symmetric peaks around the announcements, large surprises - particularly those in nonfarm payroll figures - induce severe jumps in all volatility components during the minute after news arrival. This is followed by a gradual decline lasting approximately 30 minutes thereafter. Second, noise volatility reacts relatively more strongly to news than does efficient volatility. The relative proportion of noise volatility in conditional return variances is highest before and at the announcement. While the average noise ratio prior to news arrivals is approximately $5 \%$, this proportion peaks slightly before the announcement, revealing evidence of an overshooting of noise-driven volatility, which is re-balanced and reaches its minimum of approximately $1 \%$ half an hour later. This 
indicates that volatility patterns after news announcements are clearly dominated by informational volatility, reflecting that traders tend to disagree about the "true" reaction of the efficient price. Third, we observe a concave (convex) relationship between efficient (noise-driven) volatility and the magnitude of surprises indicating that large surprises are interpreted to be "too large to be reliable". Fourth, net order flow has a significantly positive impact on both efficient and noise-driven volatility and amplifies news-driven effects. Fifth, we observe an ask volatility that is systematically higher than the bid volatility. This is also reflected in the relative noise shares in the ask volatility and spread volatility.

Overall, we find that the relative share of the noise variance is around 3\%, which is relatively low and indicates the high liquidity as well as the low degree of market friction in BUND futures trading. Nevertheless, our model and analysis provide insights into the impact of (non-anticipated) information on the noise component. The corresponding changes of the relative noise proportion dependent on the timing of announcements and the characteristics of news shed some light on the informational efficiency of the market, how market participants interpret information and how this is translated into prices. Applying the proposed framework to other announcements and markets represents a clear agenda for future research. 


\section{Appendix}

Table 1: Variables and Notation

\begin{tabular}{ll}
\hline \hline$n f$ & Nonfarm payroll surprise. \\
un & Unemployment rate surprise. \\
$n o f$ & Net order flow: absolute difference of buyer and \\
& seller initiated trading volume during a given \\
& 1-min. interval, divided by the average \\
& daily trading volume, in absolute value. \\
& Trading volume over the 1-min. interval. \\
$D_{t \in\left(t_{1}, t_{2}\right]}$ & Dummy, equal to 1 if $t \in\left(t_{1}, t_{2}\right]$. \\
$D_{\text {large }}$ & Dummy, equal to 1 if $n f>$ than the $75 \%$ quantile. \\
$\pi_{h}$ & Dummy, equal to 1 if $n f$ is of high precision. \\
& $=n f \times D_{t \in(2: 29,2: 30]}$ \\
$n f_{0}$ & $=n f \times D_{t \in(2: 30,2: 31]}$ \\
$n f_{1}$ & $=n f \times D_{t \in(2: 30,2: 31]} \times \pi_{h}$ \\
$n f_{1, P}$ & $=n f \times D_{t \in(2: 30,2: 31]} \times D_{\text {large }}$ \\
$n f_{1, L}$ & $=n f \times D_{t \in(2: 31,2: 32]}$ \\
$n f_{2}$ & $=n f \times D_{t \in(2: 31,2: 32]} \times \pi_{h}$ \\
$n f_{2, P}$ & $=n f \times D_{t \in(2: 31,2: 32]} \times D_{\text {large }}$ \\
$n f_{2, L}$ & $=u n \times D_{t \in(2: 29,2: 30]}$ \\
$u n_{0}$ & $=u n \times D_{t \in(2: 30,2: 31]}$ \\
$u n_{1}$ & $=u n \times D_{t \in(2: 31,2: 32]}$ \\
$u n_{2}$ & $=n o f_{t} \times D_{t \in(2: 30,2: 31]}$ \\
$n o f_{1}$ & $=n o f_{t} \times D_{t \in(2: 32,2: 35]}$ \\
$n o f_{2-5}$ & $=n o f_{t} \times D_{t \in(2: 35,2: 45]}$ \\
$n o f_{6-15}$ &
\end{tabular}


Table 2: QML estimation results for model (1)-(3) with constant variances for different model specifications of the conditional mean functions

\begin{tabular}{|c|c|c|c|c|c|c|c|}
\hline & & (A) & (B) & (C) & (D) & $\overline{(E)}$ & $\overline{(F)}$ \\
\hline$\mu$ & $c$ & 0.0014 & 0.0014 & 0.0014 & -0.0003 & -0.0003 & -0.0003 \\
\hline \multirow[t]{3}{*}{$\mathbf{F}$} & $\phi_{a}$ & $-0.4648 * * *$ & $-0.4647 * * *$ & $-0.4645 * * *$ & $-0.4649 * * *$ & $-0.4643 * * *$ & $-0.4644 * * *$ \\
\hline & $\phi_{b}$ & -0.4416 *** & $-0.4415^{* * *}$ & $-0.4424 * * *$ & $-0.4409 * * *$ & $-0.4406 * * *$ & $-0.4404 * * *$ \\
\hline & $\phi_{m}$ & -0.0155 & -0.0161 & -0.0166 & $-0.0451 *$ & $-0.0506 *$ & $-0.0512 * *$ \\
\hline \multirow[t]{8}{*}{$\boldsymbol{\beta}_{a}$} & $n f_{0}$ & $-1.9536 * * *$ & $-1.9521 * * *$ & $-1.9624 * * *$ & $-1.8969 * *$ & $-1.8999 * *$ & $-1.9031^{* *}$ \\
\hline & $n f_{1}$ & -12.3680 *** & $-11.4530 * * *$ & $-20.1909 * * *$ & -19.4572 *** & -18.1894 *** & $-18.1877 * * *$ \\
\hline & $n f_{2}$ & 0.2992 & 0.2964 & 0.2949 & 0.1254 & 0.0602 & 0.0605 \\
\hline & $u n_{0}$ & $-0.6261 * *$ & $-0.6260 * *$ & $-0.6251 * *$ & $-0.6105 * *$ & $-0.6121 * *$ & $-0.6132 * *$ \\
\hline & $u n_{1}$ & $2.2288 * * *$ & $2.2468 * * *$ & 2.4683 *** & 2.1355 *** & $1.5364 * *$ & $1.5364 * *$ \\
\hline & $u n_{2}$ & $1.2455 * * *$ & $1.2462 * * *$ & $1.2442^{* * *}$ & 1.2066 & $1.1905 * * *$ & $1.1908 * * *$ \\
\hline & $n f_{1, P}$ & & -1.3031 & -1.0157 & -0.4321 & 0.7235 & 0.7224 \\
\hline & $n f_{1, L}$ & & & $10.9683 * * *$ & $10.6594 * * *$ & $10.0890 * * *$ & $10.0883^{* * *}$ \\
\hline \multirow[t]{4}{*}{$\boldsymbol{\delta}_{a}$} & $n o f_{t}$ & & & & $0.0645 * * *$ & $0.0603 * * *$ & $0.0579 * * *$ \\
\hline & $n o f_{1}$ & & & & & $0.1211^{* * *}$ & $0.1235 * * *$ \\
\hline & $n o f_{2-5}$ & & & & & $0.0315^{* * *}$ & $0.0339 * * *$ \\
\hline & $n_{0} f_{6-15}$ & & & & & & $0.0152 * * *$ \\
\hline \multirow[t]{8}{*}{$\boldsymbol{\beta}_{b}$} & $n f_{0}$ & $-1.8786 * * *$ & $-1.8770 * * *$ & $-1.8873 * * *$ & $-1.8208 * * *$ & $-1.8242 * * *$ & $-1.8274 * * *$ \\
\hline & $n f_{1}$ & $-12.2456^{* * *}$ & $-11.4661 * * *$ & $-20.0852 * * *$ & $-19.3480 * * *$ & $-18.0022 * * *$ & $-18.0004^{* * *}$ \\
\hline & $n f_{2}$ & 0.3811 & 0.3784 & 0.3770 & 0.2064 & 0.1390 & 0.1392 \\
\hline & $u n_{0}$ & -0.3387 & -0.3385 & -0.3377 & -0.3228 & -0.3245 & -0.3256 \\
\hline & $u n_{1}$ & $2.1377^{* * *}$ & $2.1530 * * *$ & $2.3715 * * *$ & $2.0365 * * *$ & $1.3997^{* *}$ & $1.3997 * *$ \\
\hline & $u n_{2}$ & $1.0702 * * *$ & $1.0710 * * *$ & $1.0690 * * *$ & $1.0313 * * *$ & $1.0148 * * *$ & $1.0151 * * *$ \\
\hline & $n f_{1, P}$ & & -1.1103 & -0.8267 & -0.2383 & 0.9912 & 0.9901 \\
\hline & $n f_{1, L}$ & & & $10.8192 * * *$ & $10.5090 * * *$ & $9.9037 * * *$ & $9.9030 * * *$ \\
\hline \multirow[t]{4}{*}{$\boldsymbol{\delta}_{b}$} & $n o f_{t}$ & & & & 0.0650 *** & $0.0605 * * *$ & $0.0582 * * *$ \\
\hline & $n o f_{1}$ & & & & & $0.1287 * * *$ & $0.1310 * * *$ \\
\hline & $n o f_{2-5}$ & & & & & $0.0325 * * *$ & $0.0348 * * *$ \\
\hline & $\operatorname{nof}_{6-15}$ & & & & & & $0.0151 * * *$ \\
\hline \multirow[t]{3}{*}{$\Sigma$} & $\exp \left(\omega_{m}\right)$ & $-3.1356 * * *$ & $-3.1359 * * *$ & $-3.1561 * * *$ & $-3.3491 * * *$ & $-3.3665 * * *$ & $-3.3679 * * *$ \\
\hline & $\exp \left(\omega_{a}\right)$ & $-6.1825 * * *$ & $-6.1841 * * *$ & $-6.1973 * * *$ & $-6.1758 * * *$ & $-6.1584 * * *$ & $-6.1583 * * *$ \\
\hline & $\exp \left(\omega_{b}\right)$ & $-6.6980 * * *$ & $-6.6957 * * *$ & $-6.6741 * * *$ & $-6.7101 * * *$ & $-6.7425 * * *$ & $-6.7427 * * *$ \\
\hline
\end{tabular}

(A): No inclusion of precision asymmetries; (B) to (C): inclusion of precision effects; (D) and $(\mathrm{F})$ : inclusion of precision and liquidity effects. Sample: 1/1993-12/2005, resulting in 159 (non-overlapping) employment observations. 160-min. windows around announcements (-80 min. to +80 min.). Standard errors are computed based on QML estimates. ***, ** and $*$ indicates significance at the $1 \%, 5 \%$, and $10 \%$ level, respectively. 
Table 3: Likelihood ratio tests of the individual specifications against each other

\section{Panel I}

$\begin{array}{clccc}(\mathrm{B}) & (\mathrm{C}) & (\mathrm{D}) & (\mathrm{E}) & (\mathrm{F}) \\ 10.4 * * * & 511^{* * *} & 5342^{* * *} & 5805^{* * *} & 5841^{* * *} \\ & 501 * * * & 5332^{* * *} & 5795^{* * *} & 5831^{* * *} \\ & & 4831^{* * *} & 5294^{* * *} & 5330^{* * *} \\ & & & 463 * * * & 499 * * * \\ & & & & 35.8 * * *\end{array}$

\section{Panel II}

\begin{tabular}{|c|c|c|c|c|c|}
\hline & (B.ask) & (C.ask) & (D.ask) & (E.ask) & (F.ask) \\
\hline (A.ask) & $158 * * *$ & $80 * * *$ & $210 * * *$ & $312 * * *$ & $490 * * *$ \\
\hline (B.ask) & & - & $52 * * *$ & - & 332 *** \\
\hline (C.ask) & & & $290 * * *$ & 392 *** & $570 * * *$ \\
\hline (D.ask) & & & & - & $280 * * *$ \\
\hline (E.ask) & & & & & $178^{* * *}$ \\
\hline & (B.bid) & (C.bid) & (D.bid) & (E.bid) & (F.bid) \\
\hline (A.bid) & $198 * * *$ & 0 & $268 * * *$ & $12 * *$ & $666^{* * *}$ \\
\hline (B.bid) & & - & $70 * * *$ & - & $468 * * *$ \\
\hline (C.bid) & & & $268 * * *$ & $12 * * *$ & 666 *** \\
\hline (D.bid) & & & & - & $398 * * *$ \\
\hline (E.bid) & & & & & $654 * * *$ \\
\hline & (B.eff) & (C.eff) & (D.eff) & (E.eff) & (F.eff) \\
\hline (A.eff) & $18 * * *$ & $118 * * *$ & $144 * * *$ & $2306 * * *$ & $2350 * * *$ \\
\hline (B.eff) & & - & 126 *** & - & 2332 *** \\
\hline (C.eff) & & & $26 * * *$ & $2188 * * *$ & 2232 *** \\
\hline (D.eff) & & & & - & 2206 *** \\
\hline (E.eff) & & & & & $44^{* * *}$ \\
\hline
\end{tabular}

Panel I: Test of models (A) through (F) given in Table 2.

Panel II: Test of models (A) through (F) given in Table 4. $* * *, * *$ and $*$ indicates significance at the $1 \%, 5 \%$, and $10 \%$ level, respectively. 
Table 4: Estimation results for EGARCH models for (4) based on updated Kalman filter residuals stemming from the estimates in Table 2

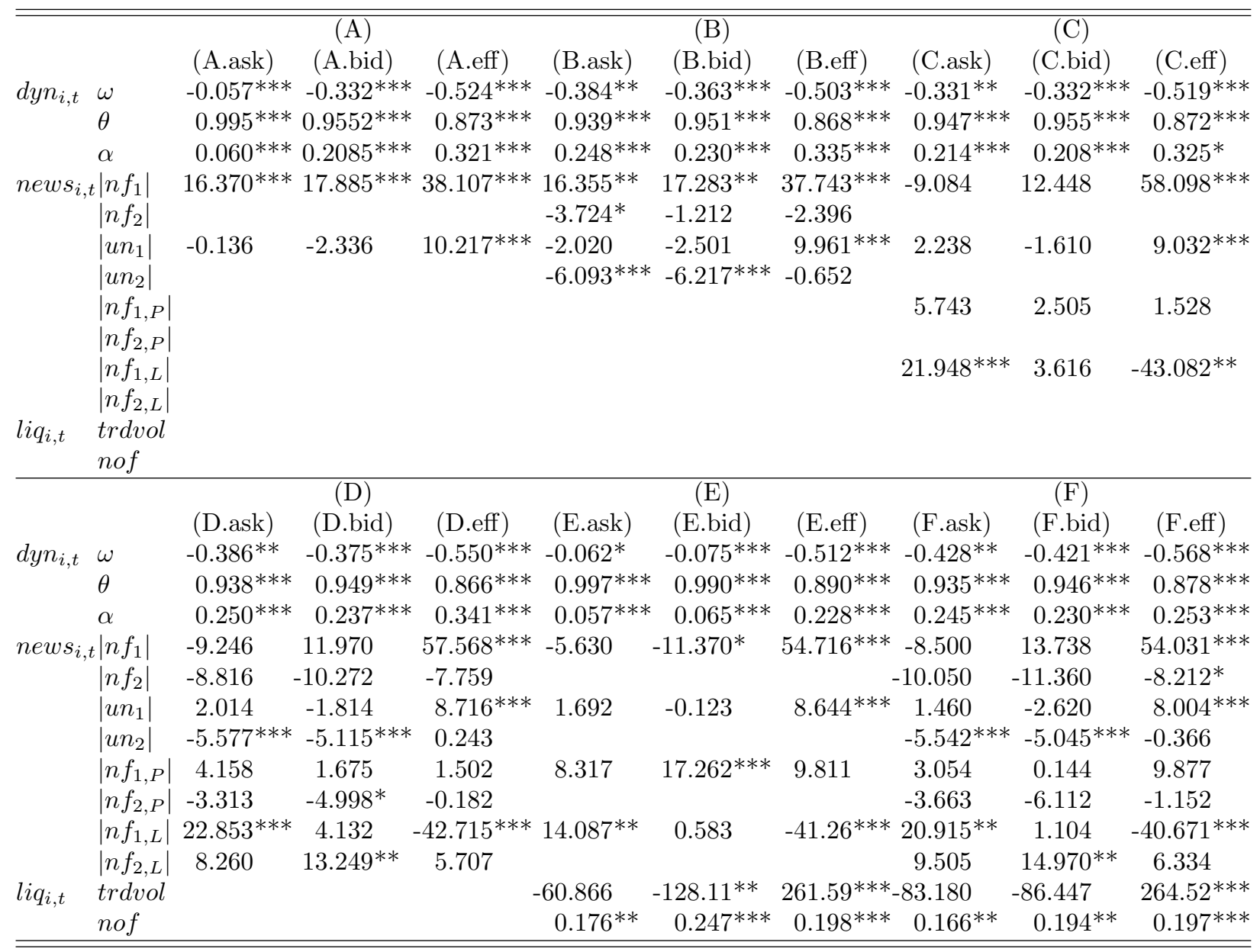

Columns (X.ask), (X.bid) and (X.eff) refer to the volatility equations for $h_{a, t}, h_{b, t}$, and $h_{m, t}$, respectively. (A) and (B): inclusion of news 1 min. and 2-5 min. after the announcements; (C) and (D): inclusion of news and precision effects 1 min. and 2-5 min. after the announcements; (E) and (F): inclusion of news, precision effects and market variables (trading volume and net order flow) 1 min. and 2-5 min. after the announcements. Sample: 1/1993-12/2005, resulting in 159 (non-overlapping) employment observations. 160 -min. windows around announcements (-80 min. to $+80 \mathrm{~min}$.) resulting in 25.440 one-minute return observations. Standard errors are computed based on QML estimates. ${ }^{* * *},{ }^{* *}$ and ${ }^{*}$ indicates significance at the $1 \%, 5 \%$, and $10 \%$ level, respectively. 
Table 5: Median marginal effects of news announcements on the conditional variances of quotes, midquotes and spreads for the different model specifications (A to F)

\begin{tabular}{lrrrrrrrrrrrrrr}
\hline \hline & (A.ask) & (A.bid) & (B.ask) & (B.bid) & (C.ask) & (C.bid) & (D.ask) & (D.bid) & (E.ask) & (E.bid) & (F.ask) & (F.bid) \\
$n f_{1}^{*}$ & 1.132 & 1.132 & 1.122 & 1.122 & 1.720 & 1.720 & 1.705 & 1.705 & 1.364 & 1.364 & 1.356 & 1.356 \\
$n f_{2}^{*}$ & & & -0.071 & -0.071 & & & -0.230 & -0.229 & & & -0.206 & -0.206 \\
$u n_{1}^{*}$ & 0.303 & 0.303 & 0.296 & 0.296 & 0.267 & 0.267 & 0.258 & 0.258 & 0.215 & 0.215 & 0.201 & 0.201 \\
$u n_{2}^{*}$ & & & -0.019 & -0.019 & & & 0.007 & 0.007 & & & -0.009 & -0.009 \\
$n f_{1, P}^{*}$ & & & & & 0.045 & 0.045 & 0.044 & 0.044 & 0.244 & 0.244 & 0.248 & 0.248 \\
$n f_{2, P}^{*}$ & & & & & & & -0.005 & -0.005 & & & -0.028 & -0.028 \\
$n f_{1, L}^{*}$ & & & & & -1.275 & -1.275 & -1.265 & -1.265 & -1.029 & -1.029 & -1.021 & -1.021 \\
$n f_{2, L}^{*}$ & & & & & & & 0.169 & 0.169 & & & 0.159 & 0.159 \\
\hline & (A.mq) & (A.spr) & (B.md) & (B.spr) & (C.mq) & (C.spr) & (D.mq) & (D.spr) & (E.mq) & (E.spr) & (F.mq) & (F.spr) \\
$n f_{1}^{*}$ & 1.132 & 0.000 & 1.122 & 0.000 & 1.720 & 0.000 & 1.705 & 0.000 & 1.364 & 0.000 & 1.356 & 0.000 \\
$n f_{2}^{*}$ & & & -0.071 & 0.000 & & & -0.229 & 0.000 & & & -0.206 & 0.000 \\
$u n_{1}^{*}$ & 0.303 & 0.000 & 0.296 & 0.000 & 0.267 & 0.000 & 0.258 & 0.000 & 0.215 & 0.000 & 0.201 & 0.000 \\
$u n_{2}^{*}$ & & & -0.019 & 0.000 & & & 0.007 & 0.000 & & & -0.009 & 0.000 \\
$n f_{1, P}^{*}$ & & & & & 0.045 & 0.000 & 0.044 & 0.000 & 0.244 & 0.000 & 0.248 & 0.000 \\
$n f_{2, P}^{*}$ & & & & & & & -0.005 & 0.000 & & & -0.028 & 0.000 \\
$n f_{1, L}^{*}$ & & & & & -1.275 & 0.000 & -1.265 & 0.000 & -1.029 & 0.000 & -1.021 & 0.000 \\
$n f_{2, L}^{*}$ & & & & & & & 0.169 & 0.000 & & & 0.159 & 0.000 \\
\hline \hline
\end{tabular}

The top panel shows the median marginal effects of the news variables in $\mathbf{x}_{t}^{v}$ on the conditional variances of the observed quotes, $\sigma_{a, t}^{2}$ and $\sigma_{b, t}^{2}$ based on specifications A to $\mathrm{F}$ (see legend of Table 4). The bottom panel shows the median marginal effects of the news variables in $\mathbf{x}_{t}^{v}$ on the conditional variances of the observed midquote and spread, $\sigma_{m q, t}^{2}$ and $\sigma_{s p r, t}^{2}$ based on model specifications A to F. 
Figure 1: Estimated median patterns of volatility components around the announcements

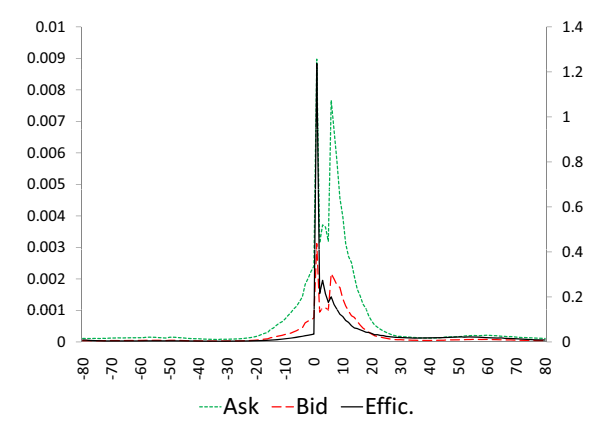

(a) $h_{i, t}$

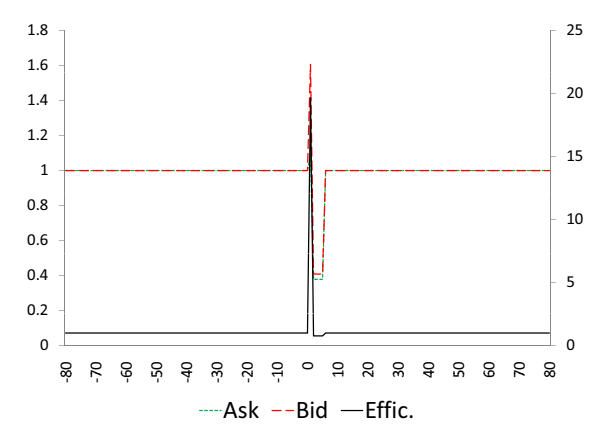

(c) news $s_{i, t}$

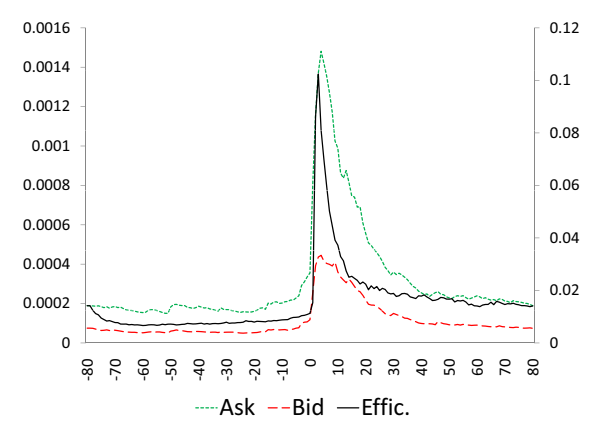

(b) $d y n_{i, t}$

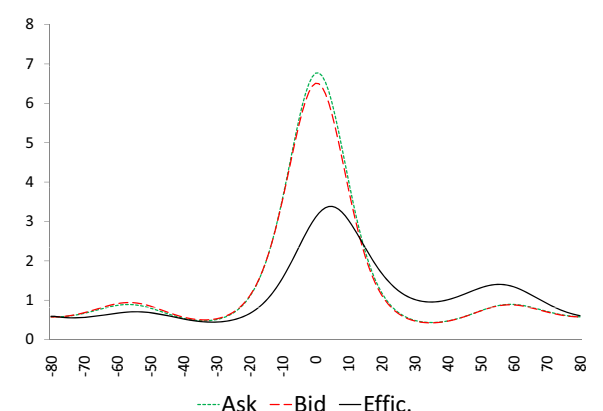

(d) $\operatorname{ton}_{i, t}$

Note: For $h_{i, t}, d y n_{i, t}$ and news $s_{i, t}$ the left axes gives the scale of ask and bid noise components whereas the right axes gives the scale of the efficient volatility. All plots are based on model (D) in Table 4. 
Figure 2: Estimated median patterns of volatility components around the announcements

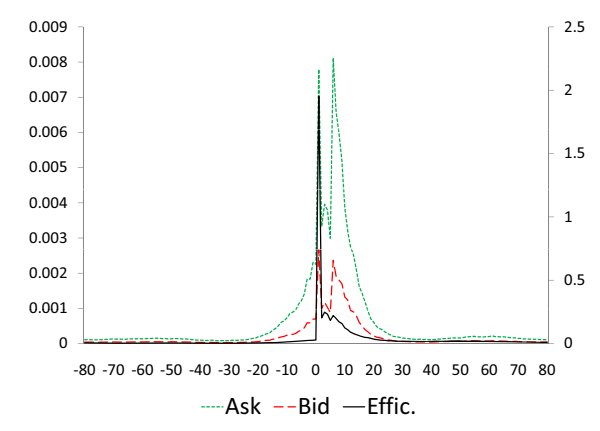

(a) $h_{i, t}$

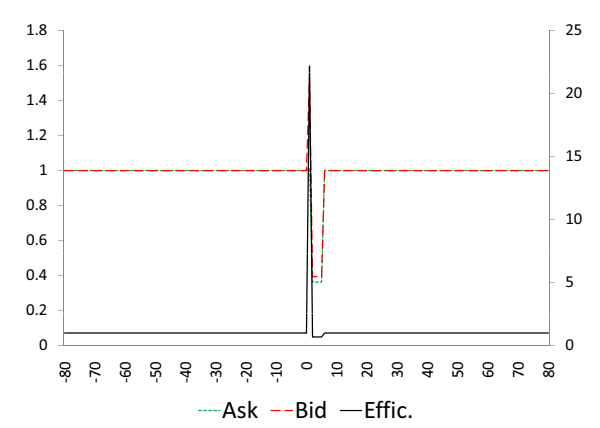

(c) news $s_{i, t}$

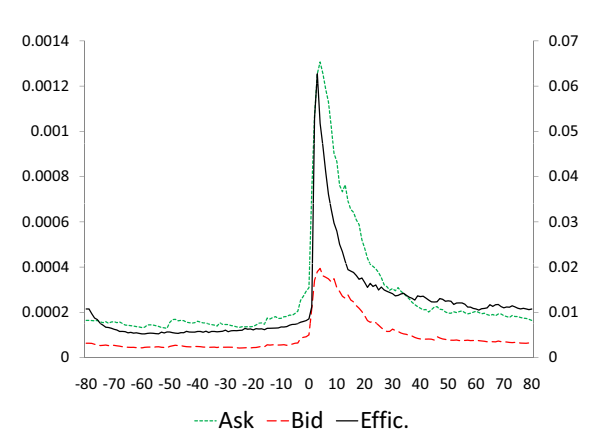

(b) $d y n_{i, t}$

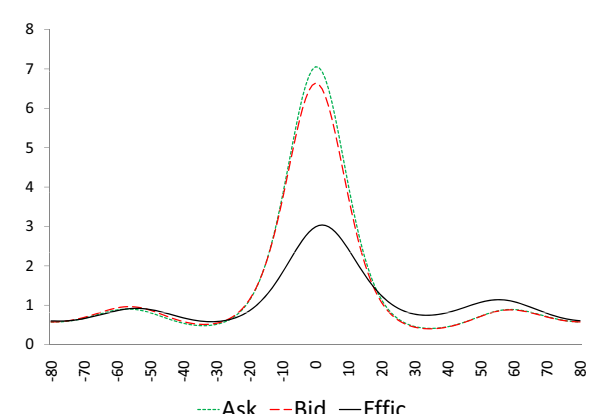

(d) $\operatorname{ton}_{i, t}$

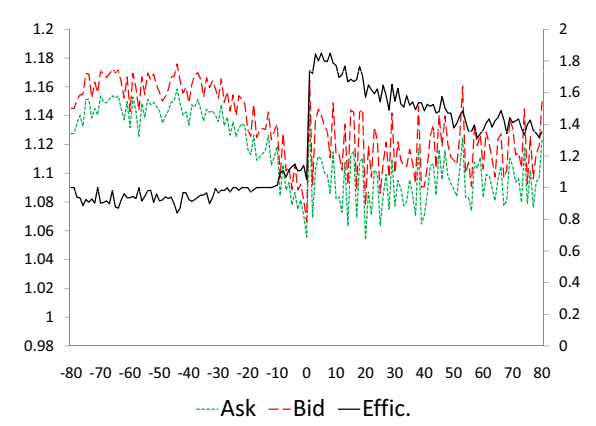

(e) $l i q_{i, t}$

Note: For $h_{i, t}, d y n_{i, t}$ and news $s_{i, t}$ the left axes gives the scale of ask and bid noise components whereas the right axes gives the scale of the efficient volat 39 lity. All plots are based on model (F) in Table 4. 
Figure 3: Estimated median patterns of information variance ratios around announcements based on specification (D)

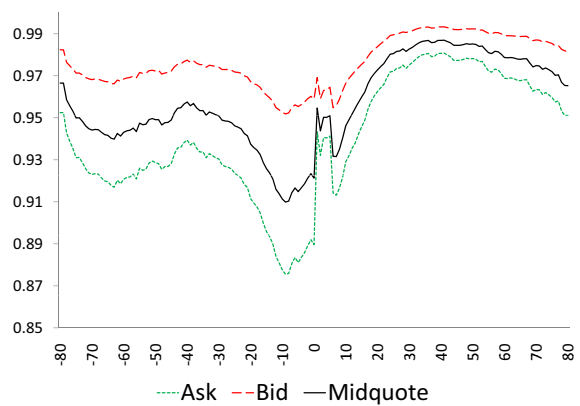

(a) $I V R_{t}^{a}, I V R_{t}^{b}$ and $I V R_{t}^{m q}$

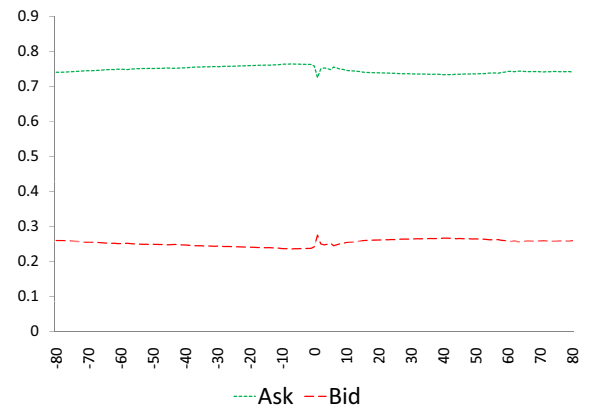

(b) $I V R_{t}^{s p r, a}$ and $I V R_{t}^{s p r, b}$

Figure 4: Estimated median patterns of information variance ratios around announcements based on specification (F)

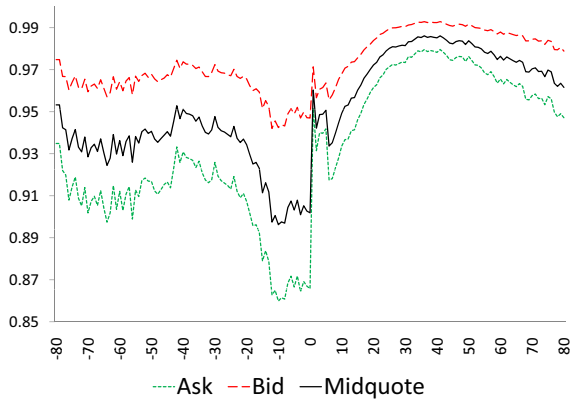

(a) $I V R_{t}^{a}, I V R_{t}^{b}$ and $I V R_{t}^{m q}$

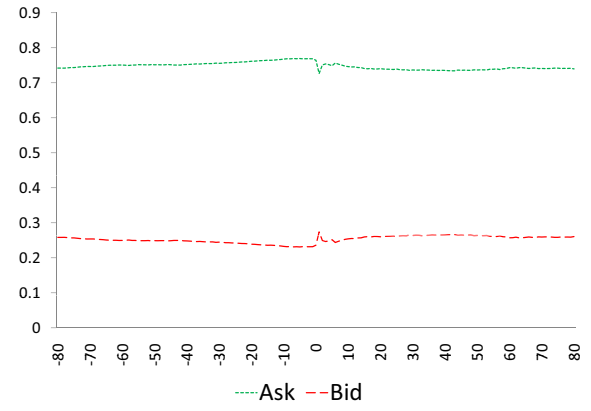

(b) $I V R_{t}^{s p r, a}$ and $I V R_{t}^{s p r, b}$ 


\section{References}

AïT-Sahalia, Y., And P. Mykland (2005): "How Often to Sample a ContinuousTime Process in the Presence of Market Microstructure Noise," Review of Financial Studies, 18, 351-416.

Andersen, T., T. Bollerslev, F. Diebold, and J. Wu (1995): "A Framework for Exploring the Macroeconomic Determinants of Systematic Risk," American Economic Review, 95, 398-404.

Andersen, T. G., T. Bollerslev, F. X. Diebold, and C. Vega (2003): "Micro Effects of Macro Announcements: Real-Time Price Discovery in Foreign Exchange," American Economic Review, 93(1), 38-62.

(2007): "Real-time Price Discovery in Stock, Bond and Foreign Exchange Markets," Journal of International Economics, 73(1), 251-277.

Andersson, M., L. J. Overby, and S. Sebestyén (2009): "Which News Moves the Euro Area Bond Market?," German Economic Review, 10, 1-31.

Barndorff-Nielsen, O. E., P. R. Hansen, A. Lunde, and N. Shephard (2009): "Subsampling Realized Kernels," Forthcoming in Journal of Econometrics.

Beine, M., J. Lahaye, S. Laurent, C. Neely, and F. Palm (2006): "Central Bank Intervention and Exchange Rate Volatility, its Continuous and Jump Components," Federal Reserve Bank of Saint Louis, WP 2006-031C.

Christie-David, R., And M. Chaudhry (1999): "Liquidity and maturity effects around news releases," Journal of Financial Research, 22(1), 47-67.

Ederington, L. H., And J. H. LeE (1993): "How markets process information: News releases and volatility," Journal of Finance, 48(4), 1161-1191.

Engle, R. (2002): "New frontiers for ARCH models," Journal of Applied Econometrics, 17, 425-446. 
Engle, R., And J. RAngel (2008): "The Spline-GARCH Model for Low-Frequency Volatility and Its Global Macroeconomic Causes," Review of Financial Studies, 21, $1187-1223$.

Engle, R. F., And A. J. Patton (2004): "Impacts of Trades in an Error-Correction Model of Quote Prices," Journal of Financial Markets, 7, 1-25.

Escribano, A., and R. Pascual (2006): "Asymmetries in Bid and Ask Responses to Innovations in the Trading Process," Empirical Economics, 30, 913-946.

Fleming, M. J., And E. M. Remolona (1999a): "The term structure of announcement effects," Discussion paper, Federal Reserve Bank of New York.

- (1999b): "What Moves Bond Prices," Journal of Portfolio Management, 25(4), $28-38$.

Foster, F., And S. Viswanathan (1996): "Strategic trading when agents forecast the forecasts of others," Journal of Finance, 51, 1437-1478.

Franke, G., And D. Hess (2000): "Information diffusion in electronic and floor trading," Journal of Empirical Finance, 7(5), 455-478.

Gallant, R. A. (1981): "On the Bias in Flexible Functional Forms and an Essential Unbiased Form: The Fourier Flexible Form," Journal of Econometrics, 15, 211-245.

Gouriéroux, C., A. Monfort, and A. Trognon (1984): "Pseudo Maximum Likelihood Methods: Theory," Econometrica, 52, 681-700.

Green, T. C. (2004): "Economic News and the Impact of Trading on Bond Prices," Journal of Finance, 56(3), 1201-1233.

Hansen, P. R., And A. Lunde (2006): "Realized Variance and Market Microstructure Noise," Journal of Business and Economics Statistics, 24, 127-218.

HARris, M., AND A. RAVIV (1993): "Difference of opinion make a horse race," Review of Financial Studies, 6(3), 473-506. 
Harvey, A. C. (1992): Forecasting, Structural Time Series Models and the Kalman Filter. Cambridge University Press.

HASBRouCK, J. (1991): "Measuring the Information Content of Stock Trades," Journal of Finance, 46, 179-207.

(1993): "Assessing the Quality of a Security Market: A New Approach to Transaction Costs Measurement," Review of Financial Studies, 6, 191-212.

Hautsch, N. (2008): "Capturing common components in high-frequency financial time series: A multivariate stochastic multiplicative error model," Journal of Economic Dynamics \& Control, 32, 3978-4009.

Hautsch, N., And D. Hess (2002): "The processing of non-anticipated information in financial markets: Analyzing the impact of surprises in the employment report," European Finance Review, 6(2), 133-161.

(2007): "Bayesian Learning in Financial Markets: Testing for the Relevance of Information Precision in Price Discovery," Journal of Financial and Quantitative Analysis, 42(1), 189-208.

Hautsch, N., D. Hess, and C. Müller (2008): "Price Adjustment to News with Uncertain Precision," Discussion Paper 2008-25, Collaborative Research Center 649 "Economic Risk", Humboldt-Universität zu Berlin.

Hautsch, N., And R. Huang (2009): "The Market Impact of a Limit Order," Discussion Paper 2009-51, Collaborative Research Center 649 "Economic Risk", HumboldtUniversit'at zu Berlin.

Kandel, E., And N. D. Pearson (1995): "Differential Interpretation of Public Signals and Trade in Speculative Markets," Journal of Political Economy, 103(4), 831872 .

KAndel, E., And B.-Z. Zilberfarb (1999): "Differential Interpretation of Information in Inflation Forecasts," Review of Economics and Statistics, 81(2), 217-226. 
Kyle, A. (1985): "Continous Auctions and Insider Trading," Econometrica, 22(6), 477-498.

Madhavan, A., M. Richardson, and M. Roomans (1997): "Why Do Security Prices Changes? A Transaction-Level Analysis of NYSE Stocks," Review of Financial Studies, 10 (4), 1035-1064.

Nelson, D. (1991): "Conditional Heteroskedasticity in Asset Returns: A New Approach," Journal of Econometrics, 43, 227-251.

Pascual, R., And D. Veredas (2010): "Does the Limit Order Book Matters in Explaining Long Run Volatility?," Journal of Financial Econometrics, 8 (1), 57-87.

Pasquariello, P., and C. Vega (2007): "Informed and strategic order flow in the bond markets," Review of Financial Studies, 20(6), 1975-2019.

Schwert, G. (1989): "Why does stock market volatility change over time?," Journal of Finance, 44, 1115-1153.

Subramanyam, K. R. (1996): "Uncertain Precision and Price Reactions to Information," Accounting Review, 71(2), 207-220.

Zhang, M. Y., J. R. Russele, and R. S. Tsay (2008): "Determinants of bid and ask quotes and implications for the cost of trading," Empirical Finance, 15, 656-678. 


\section{CFS Working Paper Series:}

\begin{tabular}{lll} 
No. & Author(s) & Title \\
\hline $2009 / 32$ & $\begin{array}{l}\text { Guenter W. Beck } \\
\text { Kirstin Hubrich } \\
\text { Massimiliano Marcellino }\end{array}$ & $\begin{array}{l}\text { On the importance of sectoral shocks for } \\
\text { price-setting }\end{array}$ \\
$2009 / 31$ & $\begin{array}{l}\text { Axel Groß-Klußmann } \\
\text { Nikolaus Hautsch }\end{array}$ & $\begin{array}{l}\text { Quantifying High-Frequency Market Reactions } \\
\text { to Real-Time News Sentiment } \\
\text { Announcements }\end{array}$ \\
$2009 / 30$ & Volker Wieland & $\begin{array}{l}\text { Quantitative Easing: } \\
\text { A Rationale and Some Evidence from Japan }\end{array}$
\end{tabular}

2009/29 Dimitris Georgarakos Trust, Sociability and Stock Market Giacomo Pasini Participation

2009/28 Dimitris Christelis Investing at Home and Abroad: Different Dimitris Georgarakos Costs, Different People?

2009/27 Erik Theissen

2009/26 Volker Wieland

2009/25 Tobias Cwik Volker Wieland

2009/24 Otmar Issing

2009/23 Nikolaus Hautsch Ruihong Huang
Price Discovery in Spot and Futures Markets: A Reconsideration

Fiscal Stimulus and the Promise of Future Spending Cuts: A Comment

Keynesian government spending multipliers and spillovers in the euro area

Politischer Wille oder ökonomisches Gesetz?

- Einige Anmerkungen zu einem großen

Thema -

The Market Impact of a Limit Order

Copies of working papers can be downloaded at http://www.ifk-cfs.de 